\title{
Inovação Social e Empreendedorismo Social: Uma Análise Sob a Perspectiva da Economia Solidária
}

\section{Social Innovation and Social Entrepreneurship: an Analysis From the Perspective of Solidarity Economy}

\author{
Carolina Beltrão de Medeiros $^{1}$, Luiz Claudio Ribeiro Machado ${ }^{1}$, Luísa Cherém de Araújo Pereira ${ }^{1}$, Íris \\ Calado de Almeida Costa ${ }^{1}$, Carla Pasa Gomez ${ }^{1}$
}

\author{
${ }^{1}$ Universidade Federal de Pernambuco, UFPE, Brasil \\ Correspondência: Carolina Beltrão de Medeiros. Endereço: Rua Dois Irmãos, 92, Ed. Anexo Anízio Teixeira \\ Apipucos CEP 52071440, Recife, PE. Tel.: 5581 3073-6527. E-mail: carolina.beltrao@ hotmail.com
}

Recebido: 29 de janeiro de 2017 Aceito: 01 de abril de 2017 Publicado: 01 de novembro de 2017

DOI: http://dx.doi.org/10.21714/1679-18272017v15n1.p61-72

\begin{abstract}
Resumo
As iniciativas de inovação, vistas sob a perspectiva de atender demandas para o bem estar da sociedade, são conceituadas na literatura como inovações sociais. Explorar como o empreendedorismo social está relacionado a este conceito, sob a perspectiva da economia solidária é o objetivo deste trabalho. O suporte teórico-empírico para este artigo, além de revisão bibliográfica em publicações nacionais e internacionais, está no levantamento dos trabalhos apresentados sobre os conceitos de inovação social e empreendedorismo social, considerando as possíveis intersecções entre estes e conexões com a lógica da economia solidária, dentro do universo dos trabalhos apresentados nos eventos da ANPAD, considerando os anos de 2008 a 2015. Ademais, foram realizadas entrevistas com autores dos artigos selecionados, a fim de esclarecer pontos destacados na investigação preliminar e foi construído um framework para apresentar as relações entre os três conceitos. Percebe-se, como resultados encontrados, que o conceito de economia solidária funciona como um vetor de promoção para que se projetem ideias de inovação social, sendo estes processos muitas vezes concretizados através de empreendimentos sociais.
\end{abstract}

Palavras-chave: Inovação social; Empreendedorismo social; Economia solidária.

\begin{abstract}
As innovation initiatives, the concepts of an opinion society, are conceptualized in the literature as social innovations. Exploring how social entrepreneurship is related to this concept, from a perspective of solidarity economy is the objective of this work. The theoretical-empirical support for this article, besides a bibliographical review in national and international publications, is a survey of the work on the concepts of social innovation and social entrepreneurship, considering as possible intersections between these and connections with a logic of solidarity economy, Inside Of the universe of ANPAD's work, considering the years 2008 to 2015. In addition, interviews with authors of the selected articles were carried out, an aim to clarify the highlights in the preliminary research and a framework was constructed to present as relations between the three concepts. The results show that the concept of solidarity economy functions as a vector for promoting ideas for social innovation, and these processes are often carried out through social enterprises.
\end{abstract}

Keywords: Social innovation; Social entrepreneurship; Solidarity economy.

Esta obra está licenciada sob uma Licença Creative Commons Attribution 3.0.

\section{Introdução}

A inovação social (IS), ao longo do tempo, tem sido delineada como uma forma de entender causas geradoras dos problemas sociais ao invés de apenas aliviar os seus sintomas, apresentando-se como uma forma de impulsionar o desenvolvimento regional, favorecendo melhorias ao bem-estar humano e ascensão dos processos sociais. O empreendedorismo social (ES), por outro lado, procura preencher os vazios deixados pelas empresas dos setores tradicionais da economia, tendo como principal missão a criação de valor social, enquanto os demais 
empreendimentos concentram-se prioritariamente na geração de lucro.

Alguns autores, como Dees e Anderson (2006) e Sharra e Nyssens (2009), têm aplicado o termo inovação social como se fosse uma escola de pensamento relacionada com o empreendedorismo social. E estes conceitos estariam relacionados de forma direta ou indireta ao conceito de economia solidária (esfera nacional) ou economia social (esfera internacional), que prevê uma forma de organização da produção, consumo e distribuição de riqueza centrada na valorização do ser humano e não do capital, caracterizada pela cooperação e solidariedade.

O termo economia solidária ganhou expressão no Brasil ao longo dos anos de 1990, à medida que iniciativas econômicas deste tipo despontaram no país, notabilizando-se e sendo reconhecidas por sua natureza associativa e suas práticas de cooperação e autogestão. Expandindo-se, a economia solidária veio a abranger categorias sociais e modalidades diversas de organização, tais como unidades informais de geração de renda, associações de produtores e consumidores, sistemas locais de troca, comunidades produtivas autóctones e cooperativas dedicadas à produção de bens, à prestação de serviços, à comercialização e ao crédito (GAIGER, 2003). E tem se apresentado como uma economia capaz de promover iniciativas que tenham como missão o bem estar da sociedade, que coadunam com objetivos da inovação social e do empreendedorismo social.

A abordagem do empreendedorismo social, além da lógica focada no contexto de negócios, é aberta para a criação de soluções em situações nas quais o Estado não consegue atender de maneira satisfatória às demandas sociais. Neste contexto, sujeitos tanto do meio de determinada realidade, quanto de fora, podem interferir para construir soluções às necessidades do grupo social afetado (ZUCATTO, 2015). Há uma ligação entre os termos de IS e ES e os mesmos podem ser confundidos, as relações ainda não estão suficientemente claras e há diferentes pontos de vista sobre o papel de cada um deles. A fim de explorar e analisar esta problemática, o trabalho em curso pretende responder à seguinte questão de pesquisa: "Como estão relacionados os conceitos de inovação social e empreendimento social, sob a perspectiva da economia solidária?"

Este artigo está organizado da seguinte forma: a presente sessão refere-se às considerações introdutórias, expondo o problema de pesquisa a ser tratado, as próximas fazem sucessivamente apresentações dos conceitos de economia solidária, empreendedorismo social e inovação social, respectivamente. As considerações metodológicas estão presentes na seção $3 \mathrm{e}$, em seguida, uma análise bibliométrica é apresentada, onde, a partir daí, são discutidos os principais pontos sobre o assunto abordado, através de entrevistas realizadas a autores dos artigos selecionados, expondo as suas principais considerações. A última seção tece as reflexões finais, as limitações do estudo e propostas para novos trabalhos na área.

\section{Fundamentação Teórica}

\subsection{Economia Solidária}

Como ideia central do termo economia solidária, entende-se que este é caracterizado primordialmente por um movimento econômico e social através de iniciativas de solidariedade e, segundo Menezes (2007), sob o respaldo da autoajuda, autogestão, cooperativismo, associativismo e ajuda mútua, que se distingue tanto da lógica puramente capitalista quanto da lógica puramente do Estado. Gaiger (2003) afirma que a economia solidária apresenta aspectos e características da economia camponesa no que diz respeito às relações sociais de produção e de trabalho, entendendo que a economia solidária perpassa pelas práticas de autogestão e cooperação.

Filho (2002) traz a perspectiva da economia solidária com a economia social a partir de dois universos distintos de experiências. Para o autor, economia social designa um universo formado a partir de quatro tipos organizacionais, que são: as cooperativas, as organizações mutualistas, as fundações e as associações de grande porte. A partir dessas quatro funções tem-se a relação com as características da economia solidária. $\mathrm{O}$ autor define-as como experiências que se apoiam sobre o desenvolvimento de atividades econômicas para a realização de objetivos sociais. Sobre o fenômeno da economia solidária no país, este foi desenvolvido e difundido principalmente a partir da década de 1990 através de diversos atos realizados pelos trabalhadores sob a forma de cooperativas autogestionárias (TAUILE, 2009).

A economia solidaria surge como uma expressão popular na busca de melhorias para o sistema precário de trabalho, desemprego e pobreza. Referente ao caráter político, econômico e social, Singer (1998) pontua que a economia solidária representa uma alternativa ao sistema capitalista e suas anomalias, através de transformações sociais. Nesse sentido, para Gaiger (2013), a economia solidária se manifesta no envolvimento ativo dos membros que nela atuam, na socialização dos recursos que são produzidos e no entendimento e prática dos princípios de igualdade e imparcialidade. No sentido de contextualização do termo, Borinelli, Santos e Pitaguari 
(2010) o definem como um sistema socioeconômico aberto, que é construído a partir da cooperação e solidariedade para atender às necessidades e desejos materiais e de convivência, a partir de movimentos democráticos, participativos e de autogestão, visando quesitos individuais, comunitários, sociais, ambientais e que visam, além de novas formas de convivência, aos benefícios gerados a partir de relações de reciprocidade, em vez da competição e do individualismo.

Os estudiosos da economia solidária convergem quanto a alguns pontos sobre a evolução e impactos do tema aqui discutido. Em primeiro lugar, sob a perspectiva de mudanças geradas no modelo de acumulação capitalista; no plano ideológico e político, as experiências solidárias atestaram sua viabilidade e capacidade de trazer benefícios à população e aos entornos sociais, despertando o interesse pelo tema de ativistas e intelectuais, multiplicando o número de projetos e agentes da economia solidária (GAIGER, 2013).

Mesmo sendo apresentada pelos seus principais teóricos e entendida neste trabalho como uma alternativa aos efeitos prejudiciais do capitalismo para a sociedade, é importante destacar estudos que apresentem divergências e choques entre a economia solidária e o capitalismo a partir do momento em que práticas típicas deste último se inserem nas bases da economia solidária. Neste sentido, Barbosa (2010) e Menezes (2007) afirmam que experiências mais fortalecidas economicamente tendem a ser mais ligadas ao mercado, o que gera uma ambiguidade na narrativa sobre economia solidaria, e que praticas capitalistas observadas na economia solidária podem gerar certos conflitos no entendimento desta, enquanto alternativa ao sistema vigente. A questão aqui apresentada faz com que "definir os empreendimentos que reúnem as qualidades necessárias para integrá-la a ser de fato uma economia solidaria se torna extremamente difícil" (LECHAT, 2004, p.42).

No processo de reestruturação do capital e do sistema capitalista vigente, no contexto da economia solidária, esta última deve então questionar e discutir não a adaptação do proletariado à lógica do capital, mas sim, outras lógicas e princípios que não apenas acomodem os trabalhadores mas que mudem as formas de organização do trabalho. Neste contexto, o empreendedorismo tem relação tanto com as atividades empresariais por conta própria, quanto com a capacidade do trabalhador assalariado de inovar. O empreendedor é visto então, como o indivíduo ou grupo de indivíduos que identificam oportunidades inovadoras para se diferenciar no mercado (ESTEVES, 2011).

Nesse contexto, o desenvolvimento para acontecer não deve estar relacionado apenas à renda, mas também à melhoria de vida de toda a população e seus entornos (SEN, 2000). Nesse novo paradigma do desenvolvimento, encontra-se a economia solidária relacionada com à perspectiva do empreendedorismo social.

\subsection{Empreendedorismo Social}

Para promover um empreendimento social, autores como Mair e Noboa (2006) advogam que o julgamento moral e a empatia influenciam muito em sua criação, assim como a percepção de viabilidade facilitada pelo apoio social e pela crença na auto-eficácia. Mas estas afirmações não limitam o empreendedorismo social (ES), visto que Hockerts (2006) relembra algumas configurações na literatura que podem ser consideradas sobre as formas de empresas sociais, tais como cooperativas e mutuamente organizações de propriedade, filiais de organizações sem fins lucrativos, cuja única finalidade é arrecadar fundos para o principal objetivo da caridade, empreendimentos com finalidade social - empresas com fins lucrativos cujo principal propósito de sua existência é criar benefícios sociais.

Elkington e Hartigan (2008) apresentam três modelos empresariais sociais: organizações sem fins lucrativos alavancadas, onde a alavancagem é feita por meio de potenciais fontes de financiamento; híbrido sem fins lucrativos, filantrópico, mas com o apoio do governo e negócio social, que obtém renda a partir de mercados mal explorados.

Em razão de vários entendimentos postos por estes e outros autores, o construto do empreendedorismo social tem sido, durante a última década, um tema em destaque que vem sendo debatido por muitos pesquisadores e que também vem sendo desenvolvido dentro de diversas iniciativas e perspectivas. Para Dees e Anderson (2006), o ES emerge da combinação dos termos empreendedorismo e social, que refletem uma quebra das barreiras que estavam entre o que poderia ser considerado como ações de negócios e ações voltadas para organizações sem fins lucrativos.

Todavia, o exercício do empreendedorismo social não se trata de uma negação de ações lucrativas. Dees e Anderson (2006) ressaltam que empreendedores sociais desempenham o papel de agentes de mudança, pois:

- Adotam a missão para criar e sustentar um valor social;

- Reconhecem e procuram incessantemente novas oportunidades para manter a missão; 
- Engajam-se em processos de inovação contínua, adaptação e aprendizagem;

- Atuam fortemente mesmo com limitação de recursos correntes à mão;

- Exibem um alto senso de prestação de contas aos envolvidos e para os resultados obtidos.

Para Auerswald (2009), simplesmente a diferença entre um empreendedor convencional e um empreendedor social é que o primeiro visa à criação de valor financeiro, enquanto o segundo visa à criação do valor social. Austin, Stevenson e Wei-Skillern (2006, p.3) propõem que "falhas no mercado podem criar diferentes oportunidades para empreendedorismo social e comercial". Os autores também alertam, além das falha mercadológicas, outras três variáveis mais descritas nas proposições teóricas sobre o assunto, sendo estas: a missão, a mobilização de recursos e mensuração de performance.

O empreendedorismo social pode ser considerado diferente do empreendedorismo comercial, mas a criação de empresas sociais não é a única forma de realizar o Empreendedorismo social. Para Sharma (2014) o Empreendedorismo social pode se manifestar por meio de iniciativas internas de organizações públicas já existentes, de empresas com fins lucrativos ou Organizações Não Governamentais (ONG’s). Existe também a possibilidade de iniciativas informais que muitas vezes se tornam inovadoras ao aproveitar recursos para um fim social. A definição do ES, em pesquisas relevantes sobre o tema, convergem como a busca de uma missão social com base no uso de estratégias sociais (BACQ; JANSSEN, 2011).

Nos Estados Unidos da América e Canadá, segundo Mendell (2010), a configuração de empreendimentos sociais possui um mix de atividades de serviço público, privada e sociedade civil. Apesar de perceptível a existência desta separação das atividades, o mesmo autor ressalta que estas são confluentes.

No entanto, atualmente, os empreendimentos sociais tem tido mais força em mercados emergentes e economias em transição. Tal força em parte é dada pelo desenvolvimento e crescimento do número de organizações da sociedade civil e da pressão por parte das ONGs para obter financiamento ou autofinanciamento (ALTER, 2003). Outra questão a ser considerada é que a obtenção de recursos aliada à liderança nas organizações sociais tem permitido seu desenvolvimento. No caso da América Latina, o BID (Banco Interamericano de Desenvolvimento) tem facilitado o apoio financeiro e técnico para as organizações sociais. Entretanto, as inovações têm ocorrido com mais frequência em ONGs que trabalham em empreendimentos sociais circunstanciais (ALTER, 2003).

Para Mendell (2010), a evolução da economia solidária e as discussões recentes sobre empreendimento social provêm de discussões anteriores, referentes à década de 1980, sobre o movimento cooperativo. Esta característica, segundo o autor, ressalta a importância de visão compartilhada de mudança social progressiva com vistas a uma inovação social.

\section{Inovação Social}

O conceito mais geral de inovação envolve processos econômicos, sendo reconhecida como estratégia com ações de busca e descoberta para desenvolver novos produtos e processos que agreguem valor às organizações, considerando o sistema econômico vigente. A inovação social (IS), além de desenvolver novas ideias, estratégias e ações relacionadas a produtos, serviços ou modelos, de acordo Phills Junior, Deiglmeier e Miller (2008), busca atender a necessidades sociais de forma mais eficiente, efetiva e sustentável do que os modelos tradicionais, criando valor social. Uma inovação é, portanto, 'social', para a extensão em que atua como ação social, ao mesmo tempo que é socialmente aceita e difundida na sociedade, através de parte dela ou de certos subgrupos (NICHOLLS; SIMON; GABRIEL, 2015).

As inovações sociais são definidas por Caulier-Grice et al (2012, p.18) como "novas soluções que, simultaneamente, atendem a necessidades sociais e guiam para novas ou melhoram a capacidade e relações de uso de bens e recursos. Em outras palavras, melhora a sociedade e sua capacidade de agir".

O termo inovação social surgiu na década de 1960 referindo-se a investigação experimental em ciências sociais e humanas. O termo também foi associado ao empreendedorismo social, inovações tecnológicas, responsabilidade social corporativa e inovação aberta. As características e os potenciais de crescimento alcançados pela IS tomaram corpo a partir do final da década de 1990 com a criação de centros de inovação social e com o crescimento das pesquisas sobre como esta inovação poderia auxiliar na resolução de problemas sociais e na melhoria da qualidade de vida (JULIANI et al., 2014). No entanto, os estudos em IS foram intensificados a partir dos anos 2000, despontando como resposta aos desafios sociais, ambientais e demográficos complexos e multifacetados, como a escassez de recursos, alterações climáticas, envelhecimento da população ou custos dos cuidados com a saúde, o impacto da globalização, entre outros (CAULIER- GRICE, et al., 2012; WARNOCK, 2014). 
Caulier-Grice et al. (2012) são pesquisadores de um centro de investigações TEPSIE, que é fruto de uma colaboração entre instituições europeias que visam à compreensão das bases teóricas, empíricas e políticas para o desenvolvimento no campo da inovação social. Dentro do entendimento das pesquisas deste grupo, são elencados cinco elementos principais que devem estar presentes para definir uma prática inovadora, conforme abaixo:

- Busca-se atender a uma necessidade social, que vai depender do contexto socialmente construído e que muitas vezes é discutível, mas pode envolver aspectos como pobreza, direitos, e desigualdades;

- A IS não precisa ser completamente original e única, mas tem que ser novidade de alguma forma para qualificar-se como tal. Nova em um campo, setor, região, mercado ou ser aplicada de uma forma nova;

- Apresenta-se com efetividade, pois deve ser mais eficaz do que aquelas soluções não atendidas de forma satisfatória pelos governos, empresas e até mesmo a sociedade. Ou seja, ela deve criar uma melhoria mensurável em termos de resultados. Tais impactos têm melhorado o bem-estar ou a coesão social em diversos aspectos;

- Dá ideia de implementação, pois reflete a aplicação prática ou a execução de uma nova ideia. Como tal, acredita-se que há uma distinção entre a formulação de uma nova ideia, a aplicação prática e a execução da referida ideia em serviços ou iniciativa viáveis e financeiramente sustentáveis;

- É projetada para melhorar a capacidade da sociedade para agir que remete à capacitação dos beneficiários pela criação de novos papéis e relacionamentos, assim como da utilização dos ativos e recursos (CAULIER-GRICE et al 2012).

Para André e Abreu (2006), a inovação social repercute numa nova forma, uma mudança social qualitativa que pode manifestar-se no sujeito, nas políticas ou nas instituições. Frequentemente está associada a um produto, porém é no âmbito dos processos que atinge maior relevância uma vez que estes agregam atributos como inclusão social, capacitação e mudança social.

De acordo com Santos (2012, p.9) "geralmente, o processo de desenvolvimento de uma inovação social inicia com um trabalho de um empreendedor social, que muitas vezes está ligada a organizações do Terceiro Setor". Porém, vale ressaltar que além do setor sem fins lucrativos, esse tipo de iniciativa emerge no setor público, privado ou na própria sociedade civil (LÉVESQUE, 2002).

Atualmente há diversidades de domínios da inovação social variados, assim, podem-se encontrar iniciativas em áreas como saúde, educação, emprego, agricultura, direitos da sociedade, entre outros. O importante é que tratam de atendimento a necessidades específicas da sociedade, beneficiando os atores locais, sendo imprescindível a participação desses agentes no processo da IS, pois o processo de inovação social não pode ser separado da legitimação do ator social que o promove ou inicia a mudança (BRUNSTEIN; RODRIGUES, KIRSCHBAUM, 2008).

Vale considerar que sempre podem ocorrer barreiras para inovação. Conforme BEPA (2010), a IS é uma tomada de risco que requer imaginação, perseverança e confiança para ser desenvolvida. No caso de sua implementação, é necessário um processo de participação e parcerias firmes, confrontando as barreiras e se expondo aos riscos. $\mathrm{Na}$ medida em que imperarem culturas organizacionais avessas aos riscos, serão fechados sistemas que favorecerão soluções como os de conhecimento mútuo, comunicação e trabalho em rede, podendo fragmentar as ações.

Portanto, em qualquer contexto onde se efetua IS, é imprescindível a participação de atores, que representam papéis fundamentais para a evolução do processo. Do ponto de vista da estruturação, a IS é socialmente construída com indivíduos engajados coletivamente em ações intencionais que reflexivamente acompanham o resultado de suas ações (CAJAIBA-SANTANA, 2014). E estes agentes sociais podem criar oportunidades no exercício da liderança dessas inovações, considerando as realidades e necessidades locais. Assim, a inovação social tem essa perspectiva em atender a uma demanda social a partir da articulação, apoio e capacidades locais, com base no incentivo de uma cultura inovadora, que empodere seus atores na busca de boas práticas (CORREIA, 2015), para que as mudanças e benefícios ocorram.

\section{Procedimentos Metodológicos}

Este é um estudo de natureza exploratória, por serem os constructos de inovação social (IS), empreendedorismo social (ES) e economia solidária emergentes na literatura, e com abordagem mista, ao passo que foi utilizado o método quantitativo para a realização de uma análise bibliométrica e, posteriormente, método qualitativo para interpretar os conteúdos dos artigos levantados e das entrevistas realizadas com os seus autores.

O trabalho foi organizado em três etapas. Inicialmente, foi realizado um levantamento bibliográfico sobre 
inovação social, empreendedorismo social e economia solidária. A revisão da literatura sobre as principais teorias que norteiam os temas abordados abrange diversas fontes de informações, a fim de apresentar os principais conceitos trazidos pelas referências consultadas, tais como artigos científicos, livros, dissertações e teses.

Num segundo momento, foi feita uma análise bibliométrica, a partir do levantamento dos artigos sobre empreendedorismo social e inovação social nos eventos da ANPAD, no período de 2008 a 2015. Com grande quantidade de trabalhos apresentados, os eventos da ANPAD são considerados, em conjunto, como o maior conglomerado de eventos em núcleo acadêmico e científico do Brasil, sendo de amplo incentivo à produção científica. Além disso, no EnANPAD, o maior evento dentre todos, os trabalhos em discussão geralmente se referem a temas de vanguarda, indicando tendências para novas investigações.

A análise foi realizada da seguinte forma: procedeu-se à verificação de todos os trabalhos que contivessem as expressões "empreendedorismo social" e "inovação social", sendo estes categorizados por evento da ANPAD, área de interesse e ano. A partir da base de dados da ANPAD, foram selecionados apenas os trabalhos que apresentaram como tema central as expressões pesquisadas, não sendo escolhidos os textos onde porventura os temas fossem citados de forma secundária. Num segundo momento, os artigos foram lidos e foram destacadas algumas características quanto ao tipo de trabalho realizado (se teórico-empírico ou ensaio teórico), à abordagem (se pesquisa qualitativa, quantitativa ou mista) e os principais achados em relação ao tema abordado em cada trabalho através de análise interpretativa. Este levantamento teve como objetivo aprofundar o conhecimento sobre os assuntos em pauta e evidenciar as abordagens em que estes conceitos têm sido utilizados no meio científico, além da verificação de possíveis conexões com os princípios norteadores da economia solidária.

Numa terceira etapa, foram realizadas entrevistas com os autores dos artigos selecionados, a fim de explorar entendimentos destes autores sobre possíveis conexões entre os conceitos. Para definição da amostra de entrevistados, utilizou-se o censo, ou seja, todos os primeiros autores foram convidados a responder à entrevista. Dos 28 artigos encontrados na revisão bibliométrica, foram observados alguns pontos operacionais para a realização das entrevistas. Do universo dos artigos sobre IS, 1 foi excluído porque uma de suas autoras faz parte do grupo de autores deste artigo, o que poderia enviesar os achados deste trabalho.

Em análise posterior, percebeu-se que havia 2 repetições de primeiro autor - desta forma, ficaram ao final 25 primeiros autores para o conjunto final. Os e-mails dos respondentes foram encontrados através de site de buscas na internet, através de critérios diversos, como o nome do autor, a palavra e-mail, dentre outros. Também foram realizadas buscas em redes sociais como Facebook e Linkedin. Apenas em 1 caso não foi possível encontrar o contato de um primeiro autor e, neste caso, procedeu-se à busca do contato do segundo autor do referido artigo. Em outro caso, o e-mail encontrado retornou para a caixa de mensagem do pesquisador remetente e não foi possível achar outro tipo de contato, nem do primeiro nem do segundo autor, apesar de recorrentes pesquisas na internet. Desta forma, a amostra final contou com 24 potenciais respondentes.

O instrumento de coleta de dados utilizado foi uma entrevista semi-estruturada, operacionalizada através da ferramenta de formulários do site Google.com e enviado por e-mail a todos os respondentes. Foi disponibilizado um link para acesso dos respondentes, onde estava presente um formulário para que fossem colocadas as devidas respostas. As perguntas propostas foram definidas a partir de temas relacionados aos pontos principais levantados na análise realizada nos artigos. Assim, buscou-se explorar os seguintes pontos: similaridades e diferenças entre inovação social e empreendedorismo social e relações entre os construtos de IS e ES com a economia solidária. Os entrevistados foram convidados a dissertar livremente sobre os questionamentos, e o convite á pesquisa chamava a atenção ainda para o anonimato das respostas, a fim de evitar qualquer tipo de constrangimento por parte dos respondentes.

As perguntas foram enviadas por e-mail durante o período aproximado de 1 mês: a cada semana, os formulários foram enviados novamente ao grupo de 24 autores, solicitando, por gentileza, que respondessem à enquete. Foram recebidas 9 respostas, configurando uma taxa de retorno de 37,5\%. No texto do convite à pesquisa, foi prometido um retorno a todo o grupo sobre os resultados da pesquisa, que deverá ser enviado a todos por escrito.

Os dados recebidos foram examinados através de análise de conteúdo, método que sistematiza, interpreta e descreve os conteúdos das informações coletadas, a fim de compreender o melhor discurso aplicado entre os entrevistados (RICHARDSON, 2008). 


\section{Análise de Resultados}

\subsection{Análise Bibliométrica}

No período de 2008 a 2015, foram encontrados 16 artigos sobre Inovação social (IS) e 12 artigos sobre Empreendedorismo social (ES), conforme demonstrado na Tabela 1. A grande concentração de artigos sobre IS está nos últimos dois anos (2014-2015), enquanto que os artigos que versam sobre ES, apresentam-se mais distribuídos ao longo do tempo, o que pode sugerir que a abordagem acadêmica de forma sistemática para o tema da Inovação social, na área de Administração, é mais recente.

Tabela 1 - Artigos sobre IS e ES, em Eventos da ANPAD, de 2008 a 2015

\begin{tabular}{ccc} 
Anos & $\begin{array}{c}\text { Inovação } \\
\text { Social }\end{array}$ & $\begin{array}{c}\text { Empreendedorismo } \\
\text { Social }\end{array}$ \\
\hline 2015 & 4 & 1 \\
\hline 2014 & 6 & \\
\hline 2013 & 0 & 4 \\
\hline 2012 & 5 & 2 \\
\hline 2011 & 0 & 1 \\
\hline 2010 & 0 & 1 \\
\hline 2009 & 0 & \\
\hline 2008 & 1 & 3 \\
\hline Total & $\mathbf{1 6}$ & $\mathbf{1 2}$ \\
\hline
\end{tabular}

Fonte: Base de dados ANPAD, de 2008 a 2015 (formatação dos autores)

Destes 28 artigos pesquisados, 1 não apresentou o conteúdo completo disponível para leitura, somente o resumo. Questionada sobre este ponto, a ANPAD respondeu que, por opção dos autores, foi disponibilizado apenas o resumo do referido artigo. Em relação ao tipo do trabalho apresentado, a maioria é do tipo teórico-empírico (vide Tabela 2), tanto nos artigos em IS (63\%), quanto nos trabalhos sobre ES (83\%). Porém, nos trabalhos em IS, há um percentual expressivo de trabalhos de cunho estritamente teórico, o que pode sinalizar uma necessidade premente de discussão de conceitos correlatos e também do próprio conceito de IS. Alguns destes temas relacionados foram abordados nestas discussões em conjunto com o tema da IS, como, por exemplo, o desenvolvimento sustentável, as tecnologias sociais, as organizações sociais.

Tabela 2 - Tipo de Trabalho dos Artigos sobre IS e ES, em Eventos da ANPAD, de 2008 a 2015

\section{Inovação}

\section{Empreendedorismo}

\begin{tabular}{lllll} 
Tipo de Trabalho & Social & \% & Social & \% \\
\hline Teórico & 6 & $38 \%$ & 2 & $17 \%$ \\
\hline Teórico-empírico & 10 & $63 \%$ & 10 & $83 \%$ \\
\hline Total & $\mathbf{1 6}$ & $\mathbf{1 0 0 \%}$ & $\mathbf{1 2}$ & $\mathbf{1 0 0 \%}$ \\
\hline
\end{tabular}

Fonte: Base de dados ANPAD, de 2008 a 2015 (formatação dos autores)

No que concerne à abordagem utilizada, a grande maioria é de caráter qualitativo (Tabela 3), tanto nos artigos sobre IS (75\%) quanto nos artigos sobre ES (83\%). Esta característica confirma uma tendência de caráter exploratório para as pesquisas em pauta, a fim de melhor compreender e interpretar os dados relativos aos conceitos de IS e ES, uma vez que ainda não há consenso entre os pesquisadores sobre seus significados e sobre a forma como estes conceitos estão relacionados.

Tabela 3 - Abordagem dos Artigos sobre IS e ES, em Eventos da ANPAD, de 2008 a 2015

\section{Inovação Social}

\begin{tabular}{|c|c|c|c|c|}
\hline Abordagem & 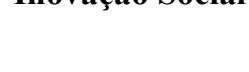 & $\%$ & Social & $\%$ \\
\hline Qualitativa & 12 & $75 \%$ & 10 & $83 \%$ \\
\hline
\end{tabular}




\begin{tabular}{ccccc}
\hline Quantitativa & 1 & $6 \%$ & 2 & $17 \%$ \\
\hline Mista & 3 & $19 \%$ & 0 & $0 \%$ \\
\hline Total & $\mathbf{1 6}$ & $\mathbf{1 0 0 \%}$ & $\mathbf{1 2}$ & $\mathbf{1 0 0 \%}$ \\
\hline
\end{tabular}

Fonte: Base de dados ANPAD, de 2008 a 2015 (formatação dos autores)

Os trabalhos apresentados sobre IS estão concentrados na área de "Inovação, Sustentabilidade e Inclusão Social" (56\%), enquanto que os trabalhos em ES foram apresentados, em sua maioria (58\%), nas áreas de "Estratégia e Empreendedorismo" e "Inovação e Empreendedorismo". Os artigos sobre ES também tendem a apresentar este conceito muito centrado na figura do empreendedor, mesmo quando a temática dos artigos não tem este assunto como o seu foco principal (existe uma área de interesse específica para este assunto, intitulada "Empreendedorismo e Comportamento Empreendedor").

Tabela 4 - Temas de Interesse dos Artigos sobre IS e ES, em Eventos da ANPAD, de 2008 a 2015

\begin{tabular}{ccccc} 
Temas de Interesse & $\begin{array}{c}\text { Inovação } \\
\text { Social }\end{array}$ & $\mathbf{\%}$ & $\begin{array}{c}\text { Empreendedorismo } \\
\text { Social }\end{array}$ & $\%$ \\
\hline $\begin{array}{c}\text { Inovação, Sustentabilidade e Inclusão } \\
\text { social }\end{array}$ & 9 & $56 \%$ & 1 & $8 \%$ \\
\hline $\begin{array}{c}\text { Inovação e Empreendedorismo } \\
\text { Relações entre Estado e Sociedade }\end{array}$ & 1 & $6 \%$ & 3 & $25 \%$ \\
\hline Estratégia e Empreendedorismo & 1 & $6 \%$ & 1 & $8 \%$ \\
\hline $\begin{array}{c}\text { Empreendedorismo e Comportamento } \\
\text { Empreendedor }\end{array}$ & 0 & $0 \%$ & 4 & $33 \%$ \\
\hline Outros & 0 & $0 \%$ & 2 & $17 \%$ \\
\hline Total & 5 & $31 \%$ & 1 & $8 \%$ \\
\hline
\end{tabular}

Fonte: Base de dados ANPAD, de 2008 a 2015 (formatação dos autores)

No que concerne à relação entre os conceitos analisados e a Economia solidária, os artigos apresentam, em maioria, a visão desta Economia como pano de fundo para as análises realizadas quando entende, por exemplo, que a IS se volta para os interesses dos grupos sociais e da comunidade, relacionando-se com projetos que melhoram a qualidade de vida dos agentes envolvidos, corroborando o entendimento de Gaiger(2013). Em outras abordagens, há trabalhos relacionando a IS à promoção do desenvolvimento sustentável, à redução de desigualdades sociais e também vinculando as Inovações Sociais a uma nova configuração do capitalismo.

Não foram encontrados artigos que abordassem os conceitos de IS e ES em conjunto, de forma que se fosse possível realizar comparações e/ou inferências. E é esta lacuna que se pretende abordar na próxima seção, onde foram analisadas as entrevistas realizadas com os autores destes artigos, a fim de explorar as possíveis intersecções entre os conceitos.

\subsection{Entrevista com Autores}

A análise dos dados coletados junto aos autores foi conduzida a partir dos seguintes passos, propostos por Creswell (2010), no que diz respeito à pesquisa qualitativa: organização e preparo dos dados para a análise; leitura de todos os dados; verificação detalhada por meio de um processo de codificação; interpretação ou extração de um significado dos dados em questão.

No que concerne às similaridades e diferenças entre inovação social (IS) e empreendedorismo social (ES), os entrevistados tiveram opiniões convergentes. A IS estaria vinculada a uma ideia que tem como objetivo principal o bem estar social e o ES estaria relacionado a uma empresa, com missão social, que pode operacionalizar uma IS. Assim, a IS seria um conceito abstrato - a ideia da inovação -, enquanto que a ES seria um conceito concreto, também fortemente atribuído à figura do indivíduo empreendedor, que desencadeia o empreendimento social. Desta forma, a IS e o ES, apesar de estarem estreitamente ligados, não representariam o mesmo conceito. Esta consideração fica bem evidente em uma das respostas (entrevistado 6):

Inovação social trata de um processo de mudança social, promovido a partir de uma 
ação coletiva em resposta a um problema público. Os processos de inovação social ocorrem, no longo prazo, e demandam uma identificação, interpretação e um codomínio de situações problemáticas, por diferentes atores que agem nas arenas públicas. O empreendedorismo social muitas vezes está associado à inovação social, mas não corresponde ao mesmo fenômeno, pois aqui estamos falando de uma ação individual ou coletiva que visa promover inovação social.

Os aspectos que aproximam os construtos de IS e ES com a economia solidária são principalmente aqueles relacionados aos objetivos dos três construtos, que relacionam-se com a promoção do bem estar social em caráter prioritário. Observando-se a economia solidária em sua conceituação geral, por si só, poder-se-ia entendê-la como uma Inovação social, uma vez que a autogestão proposta pela economia solidária, vinculada ao desenvolvimento de atividades econômicas, requer novos modelos e paradigmas. Desta forma, a economia solidária funcionaria como o suporte que promoveria as ações, primeiro de Inovação social e em seguida de Empreendedorismo social. E estes conceitos seriam entendidos de forma encadeada, conforme o entendimento do entrevistado 4.

São conceitos que se permeiam. Entretanto, a motivação e o meio de cada um é diferente. A economia solidária também é pautada na mesma ideia de ação social, mas em outro nível que não necessariamente como objetivo de um negócio. Em um ordenamento, o foco como ação social, concentra-se inicialmente no empreendedorismo social, depois na inovação social e por último na economia solidária.

A economia solidária, a inovação social e o empreendedorismo social cruzam-se no que tange a muitas características, mas, principalmente, no que diz respeito à finalidade das atividades. Numa outra resposta à indagação sobre estas relações, o entrevistado 5 comenta que se a economia solidária consegue estar mais próxima do ideal de vida em sociedade que promove os seres, mudando o olhar sobre a natureza funcionalista que se atribui aos indivíduos e criando processos inovadores para resolver velhos conhecidos problemas sociais, aí sim, ela realmente se confunde com estes conceitos de IS e ES. Como uma forma de ilustrar estas relações, foi construído um framework, conforme abaixo na Figura 1. A decisão dos autores foi expressar estas relações em um framework pelo fato de que este não apresenta uma relação causal mas, em vez disso, uma abordagem interpretativa da realidade social. $\mathrm{O}$ uso atual do termo pode ser definido como um quadro conceitual que tem planos interligados e que, juntos, oferecem uma compreensão abrangente de um fenômeno ou de vários fenômenos. Os conceitos de que são constituídos um framework fornecem mútuo suporte, articulando estes respectivos fenômenos e estabelecendo uma filosofia específica (JABAREEN, 2009).

Figura 1 - Inovação social e Empreendedorismo social, sob a perspectiva da Economia solidária

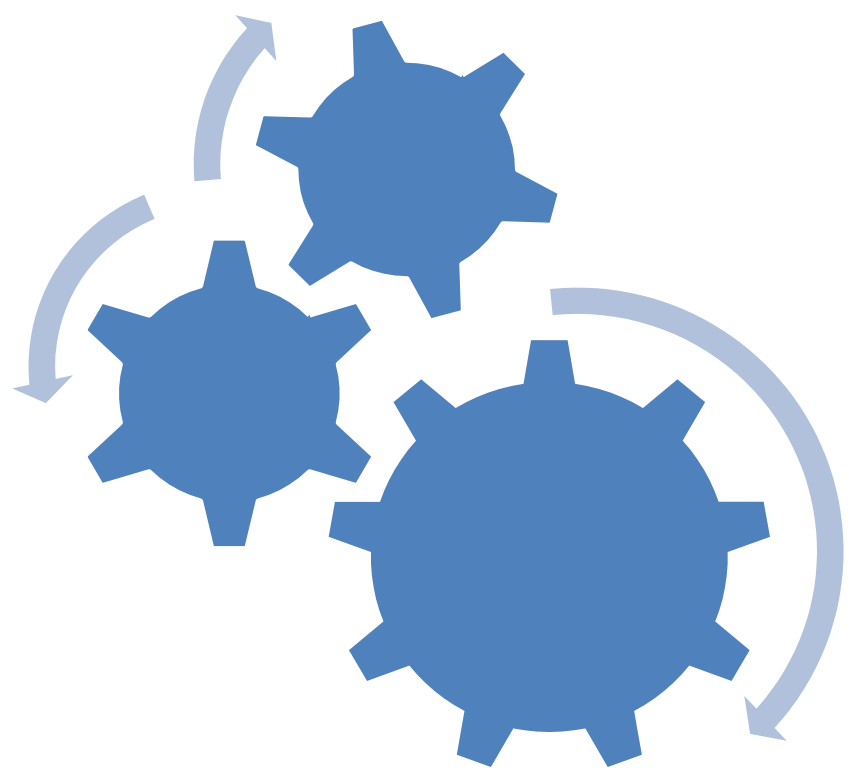

Fonte: Elaborado pelos autores (2016) 


\section{Considerações Finais}

Considerando as pesquisas encontradas nos eventos da ANPAD nos últimos 8 anos (2008-2015), organização que é referência para as pesquisas em Administração no Brasil, ainda há poucos estudos sobre inovação social e empreendedorismo social no país. Mesmo sendo a IS uma alternativa para a resolução ou abrandamento dos problemas sociais e para a crescente preocupação com as desigualdades, de diversas naturezas, geradas por um mercado extremamente competitivo, os estudos sobre a temática não representam parcela significativa das pesquisas acadêmicas, e o conjunto de abordagens, metodologias e práticas ainda não se constitui num corpo consolidado de conhecimentos (BIGNETTI, 2011). Enquanto processos de inovação voltados para o mercado (lucro) são exaustivamente estudados na academia, o campo da Inovação social precisa ser estudado em profundidade (CAJAIBA-SANTANA, 2014), por atuar em problemas muitas vezes não abordados pelas empresas e pelo Poder Público mas que são de grande importância para a sociedade.

O mesmo se observou em relação aos trabalhos sobre empreendedorismo social: ainda há poucas pesquisas sobre $\mathrm{o}$ assunto, embora que as pesquisas apresentadas tenham sido realizadas em maior parte considerando casos reais de empreendimentos sociais (trabalhos também com abordagem empírica) do que os trabalhos versando sobre inovação social, que apresentaram uma abordagem de cunho teórico mais representativa em relação às pesquisas sobre ES. Esta constatação pode sugerir que haveria menos certezas sobre o que é a Inovação social, despertando a necessidade de maiores discussões sobre o conceito.

Estas indicações foram corroboradas pelas entrevistas aos autores dos artigos: parece estar mais claro para os especialistas o conceito de empreendedorismo social, já que é um conceito mais concreto, relacionado a uma organização física e à figura do empreendedor social. Já o conceito de inovação social seria considerado como um conceito abstrato, que representaria uma ideia que pode ser realizada num empreendimento social ou não. $\mathrm{E}$ o conceito da economia solidária funcionaria como um elemento propulsor para estes tipos de iniciativas, pressupondo um certo pertencimento ideológico dos conceitos de IS e ES a este conceito. Some- se a isto considerar que a Inovação social é um conceito que ultrapassa as fronteiras do empreendedorismo social, uma vez que a solução apresentada pela Inovação social deve maximizar o valor que os empreendimentos sociais podem criar para a sociedade (SANTOS et. al., 2013).

Finalmente, vale salientar que, pelo seu caráter exploratório, este trabalho possui limitações quanto às considerações realizadas pois ele não tem prerrogativa para realizar inferências sobre estas, o que poderia ser realizado através de pesquisas descritivas, utilizando como casos iniciativas de inovação social e empreendimentos sociais. Desta forma, ficam estas considerações registradas como sugestões para trabalhos futuros na área.

\section{Referências}

ANDRÉ, I.; ABREU A. Dimensões e espaços da inovação social. Finisterra, XLI, 81, pp. 121- 141, 2006.

ALTER, S. K.. Social Enterprise: a typology of the field contextualized in Latin America. 2003.

AUERSWALD, P. E. Creating social value. Spring 2009, Stanford Social Innovation Review, 2009.

AUSTIN, J.; STEVENSON, H.; WEI-SKILLERN, J.. Social and commercial entrepreneurship: same, different, or both?. Entrepreneurship theory and practice, v. 30, n. 1, p. 1-22, 2006.

BACQ, S.; JANSSEN, F.. The multiple faces of social entrepreneurship: a review of definitional issues based on geographical and thematic criteria. Entrepreneurship \& Regional Development, v.23, n.5-6, p.373-403, 2011.

BARBOSA, R. N. C.. Trabalho e Economia solidária: elementos para pensar a desigualdade social, Universidade Federal do Rio Grande do Norte, 2010.

BEPA (BUREAU OF EUROPEAN POLICY ADVISERS) Empowering people, driving change. Social Innovation in the European Union. European Communities. Luxembourg, 2010.

BIGNETTI, L. P.. As inovações sociais: uma incursão por ideias, tendências e focos de pesquisa. Ciências Sociais Unisinos, v. 47, n. 1, 2011.

BORINELLI, B; SANTOS, L.M.L; PITAGUARI, S.O. Economia solidária em Londrina: Aspectos conceituais e a Experiência Institucional. Universidade Estadual de Londrina, 2010.

BRUNSTEIN, J.; RODRIGUES, A.L.; KIRSCHBAUM, C.. Inovação social $\mathrm{e}$ empreendedorismo institucional: a ação da ONG "Ação Educativa" no campo educacional da cidade de São 
Paulo. o\&s, v.15, n.46, jul./ set. 2008.

CAJAIBA-SANTANA, G. Social innovation: moving the field forward: a conceptual framework. Technological Forecasting and Social Change, v. 82, p. 42 - 51, 2014.

CAULIER- GRICE, J. et al. Defining Social Innovation. Part 1. The Young Fundation. Europa, 2012.

CORREIA, S. E. N. O papel do ator organizacional na inovação social. Tese (doutorado) - Programa de PósGraduação em Administração, Universidade Federal de Pernambuco, Recife- PE, 2015.

CRESWELL, J. Projeto de Pesquisa: métodos qualitativo, quantitativo e misto. 3. ed. Porto Alegre: Artmed, 2010.

DEES, G.; ANDERSON, B. B. "Framing a theory of social entrepreneurship: building on two schools of practice and thought". Research on Social Entrepreneurship, ARNOVA occasional paper series, v.1,n.3, p. 39-66, 2006.

ELKIngton, J.; HARTIGAN, P.. Creating Successful Business Models. The Power of Unreasonable People: How Social Entrepreneurs Create Markets that Change the World, p. 29-54, 2008.

ESTEVES, A.G. Economia solidária e empreendedorismo social: perspectivas de inclusão social pelo trabalho. O Social em Questão - Ano XIV - no 25/26 - 2011

FILHO, G.C.F. Terceiro setor, economia social, economa solidária e economia popular: traçando fronteiras conceituais. BAHIA ANÁLISE \& DADOS, Salvador, SEI, v.12, n1, 2002.

GAIGER, L. I. G. A economia solidária diante do modo de produção capitalista CADERNO CRH, Salvador, n. 39, p. 181-211, jul./dez. 2003.

. A economia solidária e a revitalização do paradigma cooperativo. Revista Brasileira de Ciências Sociais, v. 28, n. 82 , p. $212-227,2013$.

HOCKERTS, K. Entrepreneurial Opportunity in Social Purpose Business Ventures. In: Social entrepreneurship. Palgrave Macmillan UK, 2006. p. 121-135.

JABAREEN, Y. Building a Conceptual Framework: Philosophy, Definitions and Procedure. International Journal of Qualitative Methods, v.8, n.4., 2009.

JULIANI, D. P. et al. Inovação social: perspectivas e desafios. Espacios, v.35, n.5, 2014. LECHAT, N. M. P. Trajetórias intelectuais e o campo da Economia solidária no Brasil. Tese (doutorado) - Doutorado em Ciências Sociais, Instituto de Filosofia e Ciências Humanas, UNICAMP, Campinas-SP, 2004.

LÉVESQUE, B. Les entreprises d'économie sociale, plus porteuses d'innovations sociales que les autres? In: COLLOQUE DU CQRS AU CONGRES DE L'ACFAS, 2001, Montreal,

Cahiers du CRISES, v. 0205, 2002.

MAIR, J.; NOBOA, E.. Social entrepreneurship: How intentions to create a social venture are formed. In: Social entrepreneurship. Palgrave Macmillan UK, 2006. p. 121-135.

MENDELL, M. Reflections on the evolving landscape of social enterprise in North America. Policy and Society, v. 29, n. 3, p. 243-256, 2010.

MENEZES, M. T. C. G. de. Economia solidária: elementos para uma crítica marxista. Rio de Janeiro: Gramma, 2007.

NICHOLLS, A. J. SIMON AND GABRIEL - New Frontiers in Social Innovation Research, available at books.google.com, 2015. Acesso em 25 mai 2016.

PHILLS JUNIOR, J.A.; DEIGLMEIER, K.; MILLER, D.T. Rediscovering Social Innovation. Stanford Social Innovation Review, 2008. Disponível em 30-05-15 em:

http://www.innovationsociale.lu/sites/default/files/2008_Rediscovering\%20Social\%20Innovatio

n_Phills\%26al.pdf

RICHARDSON, R. J. Pesquisa Social: métodos e técnicas. São Paulo: Atlas, 2008.

SANTOS, F. M. A positive theory of social entrepreneurship. Journal of business ethics, v. 111, n. 3, p. 335$351,2012$.

SANTOS, F. et al. The Life Cycle of Social Innovation. In: Social Innovation: Solutions for a Sustainable 
Future. London: Springer, 2013.

SEN, A. K. Desenvolvimento como liberdade. São Paulo: Companhia das Letras, 2000.

SHARMA, M. K. A New Trend Social Enterpreneurship: Global Perspective, v1, Issue-1, August 2014.

SHARRA, R.; NYSSENS, M. Social innovation: an interdisciplinary and critical review of the concept. Acesso em $\quad 5 \quad$ jul 2015.2010 Disponível $<$ http://www.ces.ulg.ac.be/uploads/Workshop\%2034\%20March/Sharra\%20and\%20Nyssens\%20 2010.pdf>, 2009.

SINGER, P. I. Globalização e Desemprego: diagnósticos e alternativas. $7^{\circ}$ ed. São Paulo: Contexto, 1998.

TAUILE, J. R. Trabalho, Autogestão e Desenvolvimento - escritos escolhidos 1981-2005. Rio de Janeiro: Editora UFRJ, 2009. 385 p.

WARNOCK, R. Harnessing the power of social innovation to drive the Northern Ireland economy - Final draft. Department of Enterprise, Trade and Investment - DETI, 2014.

Disponível em: < http://outhouseconsulting.co.uk/research/4575037824>. Acesso em: 25 out. 2015.

ZUCATTO, L. C.. Empreendedorismo cooperativo e intercooperação na produção de energia elétrica e de alimentos: evidências do cooperativismo de eletrificação rural gaúcho. Tese (doutorado) - 